\title{
RARE LOCATIONS OF HYDATID DISEASE EVALUATED BY RADIOLOGICAL IMAGING.
}

1. MBBS, FCPS

Associate Professor Radiology HBS Medical and Dental College, Islamabad, Pakistan.

2. MBBS, FRCR, MCPS, FCPS Associate Professor Radiology AFIRI, Rawalpindi, Pakistan

3. MBBS, MRCP, FRCP, FCPS Assistant Professor Cardiology AFIC, Rawalpindi, Pakistan.

4. MBBS, DMRD, FCPS

Assistant Professor Radiology Kemu/Mayo Hospital Lahore.

5. MBBS (Final Year Student) Sargodha Medical College Sargodha.

Correspondence Address: Dr. Muhammad Umar Amin Department of Radiology HBS Medical and Dental College, Islamabad.

umaramin71@gmail.com

Article received on:

30/04/2019

Accepted for publication: $11 / 06 / 2020$
Muhammad Umar Amin'1, Mobeen Shafique ${ }^{2}$, Mohsin Saif ${ }^{3}$, Nawaz Rashid ${ }^{4}$, Muhammad Adil ${ }^{5}$

ABSTRACT... Objectives: To document unusual locations of hydatid disease by Radiological Imaging performed in a Tertiary care center. Study Design: Descriptive Case series. Setting: Department of Radiology and Imaging, HBS General Hospital, Islamabad. Period: Jan 2016 to Dec 2018. Material \& Methods: 64 cases of hydatid disease were included in our study seen between 2016 and 2018. 11 cases were retrospectively analyzed because of their unusual locations. MDCT was performed in all of our cases. Ultrasound, MRI, Color Doppler, IVU, and plain films also were performed in selected cases. Histopathological diagnosis of hydatid disease was confirmed in all cases operated surgically. Results: Rare locations of hydatid disease in this series included kidney, abdominal wall, chest wall, ovary, lumbosacral spine, iliopsoas muscles, mesentery, lung hilum, diaphragm, spleen and bronchus (in form of Broncho-pleural fistula). The Table-I, is most unusual presentations were passage of cysts in urine in a case of renal hydatid cyst, passage of cysts with haemoptysis in a case of bronchopleural fistula caused by ruptured hydatid cyst, infertility in an ovarian hydatid cyst, abdominal and chest wall swellings due to hydatid cysts. Even though there was no mortality in these patients, there was disabling morbidity. Conclusion: Hydatid disease can present with unusual symptoms and signs depending on the organ of involvement. Hydatid disease can affect any organ in the body and a high suspicion of this disease is justified in any unusual cystic lesion of any organ, Moreover, detailed imaging techniques should precede and follow the surgical intervention. Multi-imaging modalities are also more helpful in rare diffuse hydatidosis.

Key words: $\quad$ Endemic, Hydatid Disease, Imaging Techniques.

Article Citation: Amin UM, Shafique M, Saif M, Rashid N, Adil M. Rare locations of hydatid disease evaluated by radiological imaging. Professional Med J 2020; 27(8):1737-1741. DOI: 10.29309/TPMJ/2020.27.08.3659

\section{INTRODUCTION}

Cystic Echinococcosis (CE) is a neglected tropical disease in Pakistan as declared by WHO. It is larval stage disease of tapeworm that causes infection in herbivorous animals \& humans. Its prevalence is about $1 / 100,000$ in developed countries \& 2 to 3 million, Domesticated dogs \& wild carnivores may act as definitive hosts, livestock \& humans act as intermediate host. Humans becomes infected accidentally by $\mathrm{E}$. granulosus by taking food, vegetables, fruits or drinking water having its eggs at larval stage, in which multiple tiny tapeworm heads called Protoscolices are produced via asexual reproduction, a single cyst can have thousands of Protoscolices and each of it can develop into an adult worm provided that if it ingested by the definitive host. Investigations have been carried out on its prevalence in Pakistan, which highlights the significant prevalence of the disease in the Pakistani population. ${ }^{1}$

We studied 64 cases of hydatid disease between 2016 and 2018. Out of 64 diagnosed case by histopathology only 11 cases were retrospectively analyzed because of their unusual locations of the hydatid cyst. MDCT was performed in all of our cases. Ultrasound, MRI, Color Doppler, IVU, and plain films also were performed in selected cases. Histopathological diagnosis of hydatid disease was confirmed in all cases operated surgically. The hydatid cysts occur mostly in the liver $(59-75 \%)$ \& it followed by the lung $(27 \%)$, kidney (3\%), bone (1-4\%) and brain (1-2\%). Other rare sites include heart, spleen, pancreas and skeletal muscle, are also involved. ${ }^{2}$ In our 
study, the organs like ovary, abdominal wall, sacral canal, psoas muscle and lung hilum were involved which exceedingly rare given in Table-l.

Lewall recently introduced pathology-based classification on hydatid disease. ${ }^{3}$ The most common complications of hydatid disease are its rupture and secondary infection. Hydatid disease rupture is of three types. ${ }^{3,4}$ (1) That includes, contained rupture, it is clinically silent, the Endocyst, most inner layer, ruptures, in this type cyst contents are confined within the pericyst. (2) In communicating rupture, the cyst ruptures into the biliary and bronchial radicles that are incorporated in the Pericyst, most outer layer, and may result in biliary obstruction or secondary infection. (3) In Direct rupture includes rupture of both the endocyst and pericyst, with spillage of cyst contents into the peritoneal or pleural cavities or other structures. Hollow viscus rupture, such as stomach or colon, is exceedingly rare. ${ }^{5,6}$ The best treatment for abdominal hydatidosis is surgery. ${ }^{3}$ Rupture and superimposed bacterial infection may occur in hydatid cyst. ${ }^{4}$ Complications of hydatid disease include rupture and secondary infection. Rupture of hydatid cyst may be contained or communicating. ${ }^{5}$ Rupture is more commonly seen when cyst becomes larger than
$6 \mathrm{~cm} .{ }^{6}$ Since there was little knowledge, attitudes and practices of such studies in Pakistan, the objectives of this study was to determine our northern areas association with CE in a selected study area, and to provide some information for the development of intervention strategies and measures for CE in Pakistan.

\section{MATERIAL \& METHODS}

64 cases of hydatid disease were included in our study seen between 2016 and 2018. 11 cases were retrospectively analysed because of their rare locations. Uncomplicated hepatic and pulmonary hydatid cysts were excluded from the study. MDCT was performed in all of our cases. Ultrasound, MRI, Color Doppler, IVU, and plain films also were performed in selected cases to document exact morphology, unusual imaging features and rare locations of hydatid cysts. All cases in which surgery was performed were confirmed on histopathology.

\section{RESULTS}

Rare locations of hydatid disease in this series are given in Table-l. Even though there was no mortality in these patients, there was disabling morbidity.

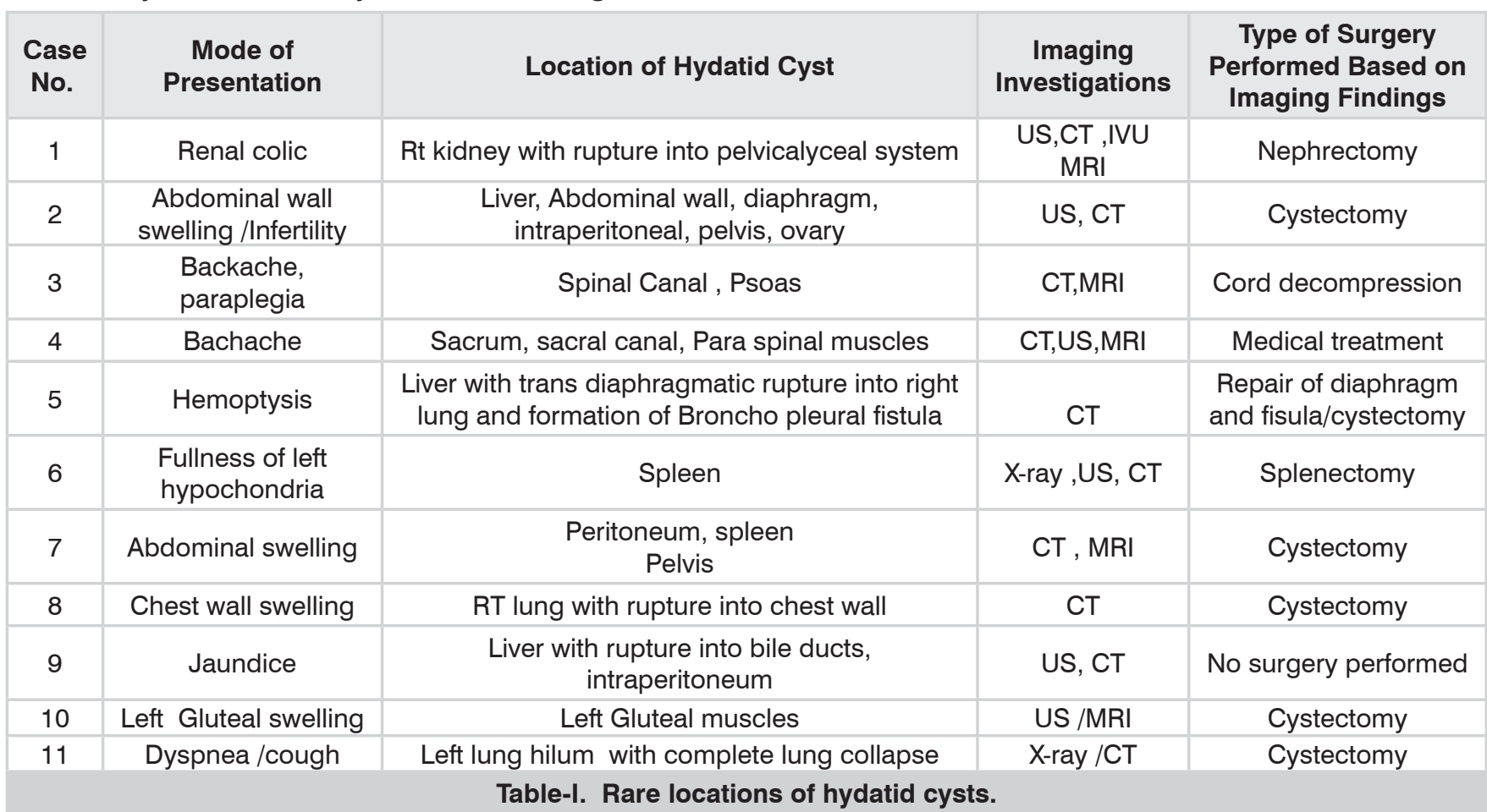




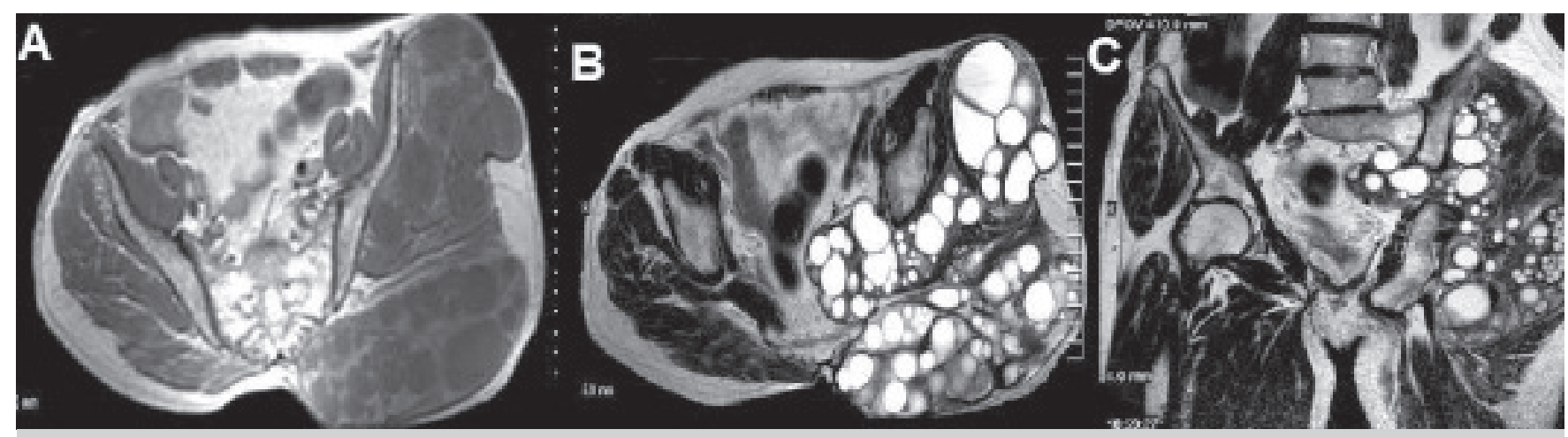

Figure-1. A, T1 B. T2 Axial C. T2 Coronal MRI. Huge Left Gluteal Hydatid cyst.

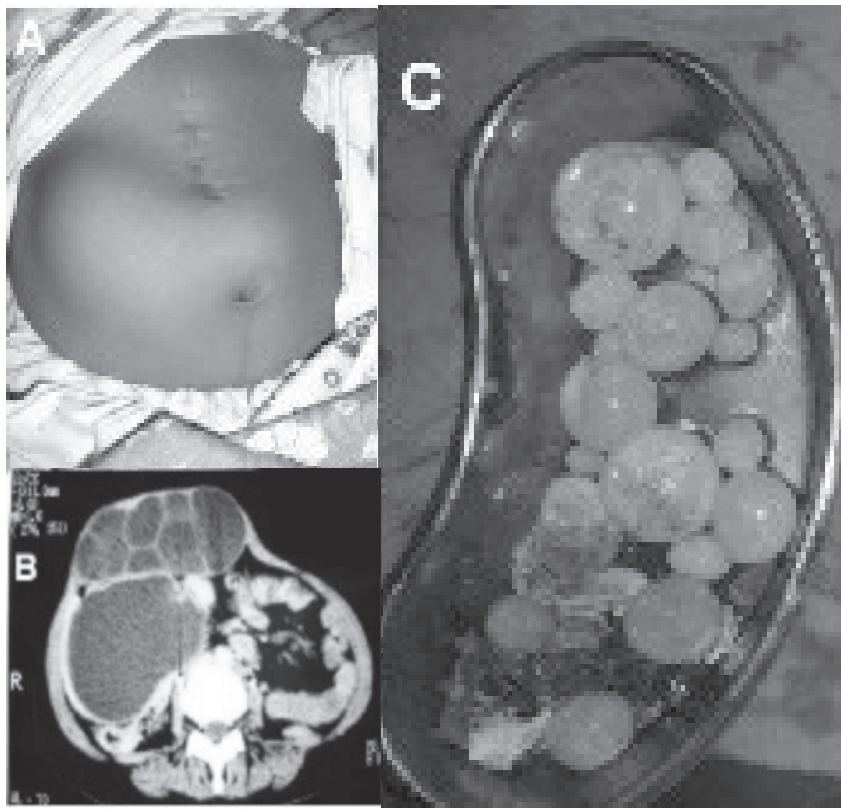

Figure-2. Hydatid cyst in abdominal wall and right sub hepatic region.

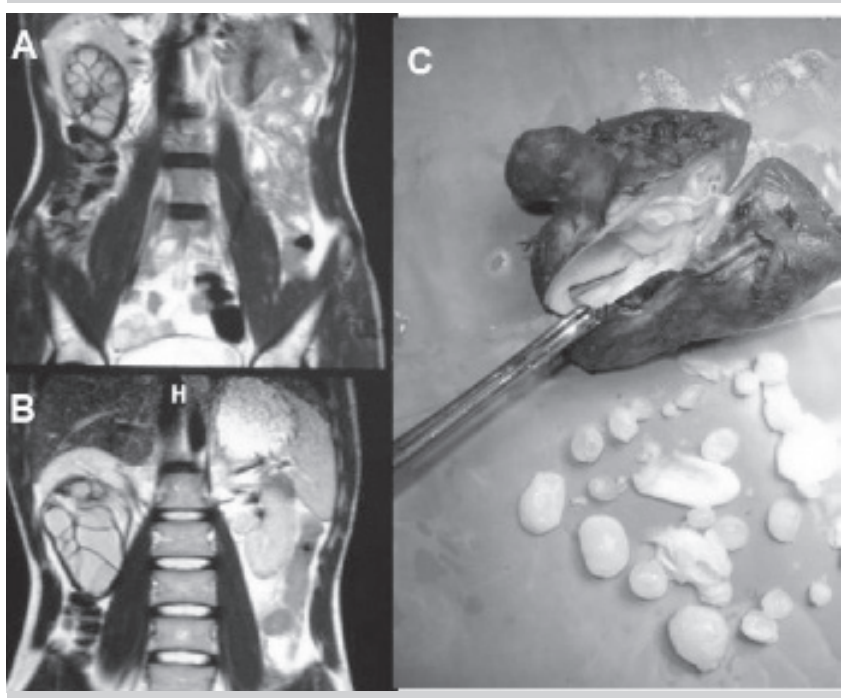

Figure-3. Right renal Hydatid cyst. A, B. Coronal MRI (T2W) C. Nephrectomy specimen.

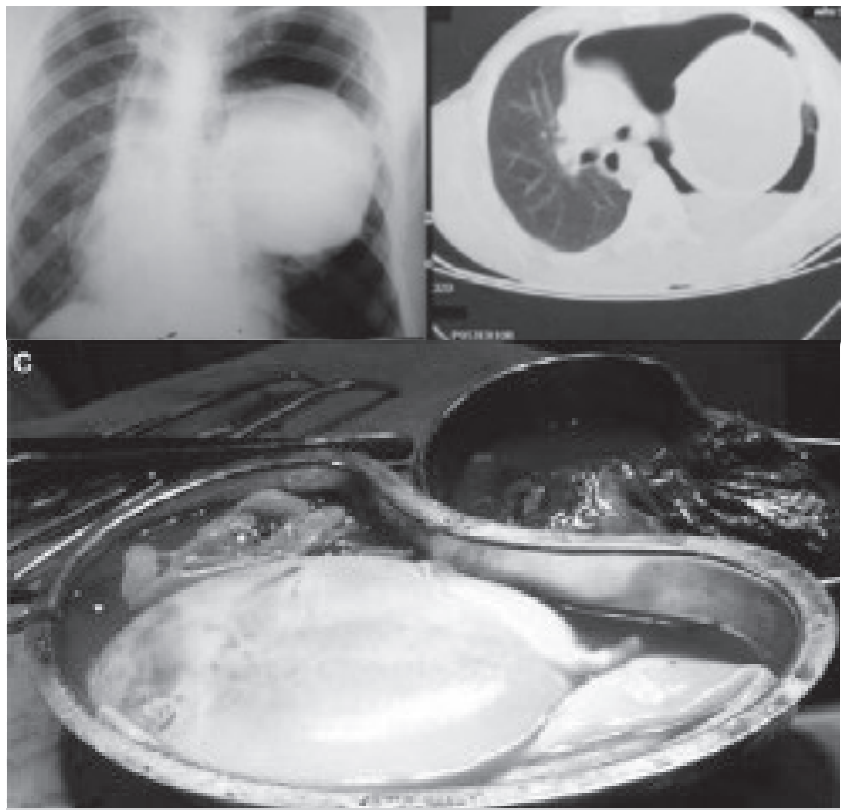

Figure-4. Left Lung Hilar Hydatid cyst. A. Chest x-ray B. CT C. Operative specimen.

\section{DISCUSSION}

A basic cause for most of these advanced stages of hydatidosis diagnosed in our study is lack of proper diagnostic facilities in Pakistan. Patients don't seek medical advice until late during the course of their illness. Diagnostic facilities are also few and far between causing a delay in diagnosis.

Collapsed membrane sign was seen in many of our cases on CT and ultrasound. This sign has a degree of specificity for diagnosis of endocyst rupture. ${ }^{7}$ A membrane like structure parallel to the outer wall is not seen in any other disease entity. No calcification is seen in the Hydatid cyst in cases of pulmonary infestation. ${ }^{8}$ We also noted the simultaneous infestation of liver and lung by 
hydatid disease in our patients. ${ }^{9}$ Disseminated hydatid disease involving other organs is rare. ${ }^{10}$

Pulmonary Hydatid cysts occur more commonly in younger Population. The most valuable diagnostic method in pulmonary hydatid disease is the plain chest X-Ray. ${ }^{11}$ Pulmonary Hydatid cysts range in size between $1.0 \mathrm{~cm}$ and $20.0 \mathrm{~cm} .{ }^{12}$ Hydatid disease in muscles is often asymptomatic with slow evolution making its diagnosis late. ${ }^{13}$

Gluteal hydatid cyst seen in our study was not suspected clinically as the patient presented with hard left gluteal swelling. A differential of large abscess and Aneurysmal bone cyst was given clinically. MRI was employed in this case and revealed classical daughter cysts. However, primary Hydatid disease of Gluteal region is very rare. Hydatid cysts may rupture after medical treatment. ${ }^{14}$

In the medical literature, reports about splenic hydatid cyst are rare. In our case, splenectomy was performed thus avoiding the risk of its rupture. ${ }^{15}$ Hydatid disease of bone is also very rare. The surgeon was suspicious of Neurofibromatosis \& Chordoma, in our case of sacral hydatid cysts before imaging was performed. MRI proved diagnostic in this case showing the multiseptated cystic sacral lesions.

Involvement of kidney by Hydatid cysts is rare (3\%). ${ }^{16}$ Pelviuretric junction stricture complication was seen in our case, smaller daughter cysts were excreted in urine in our patient was also noted which is a rare occurrence.

Alam et al have also published their data of rare locations of hydatid cysts. ${ }^{17}$ Our study documented rare locations of hydatid which were different from Alam study as we have included rarer locations of involvement. The presence of hydatid cysts in spleen, musculoskeletal system, brain, kidney and soft tissues in 10 year studies, was documented by Eylul G et al. ${ }^{18}$ Our study was of short in duration, but it also described the involvement of the musculoskeletal and renal involvement by hydatid cysts. Thus Hydatid cyst can infest any structure in the body.

\section{CONCLUSION}

The Hydatid cysts can be seen to involve Pakistani papulation in rare body sites. In Pakistan, there are many endemic regions where Hydatid disease is prevalent especially in its northern areas. Hence, the role of radiologist becomes very crucial in suspecting hydatid cysts in rare locations, especially if someone encounters cystic lesions.

We noticed that the knowledge of CE is generally little in our papulation, People did not have knowledge \& understand threats associated with dogs \& their cattle infected with CE. It is necessary to give awareness of common man about that disease \& its complications. The hydatid disease is having emerging trend in Pakistan \& further to bring this disease to limelight for research purpose.

Copyright $@ 11$ June, 2020.

\section{REFERENCES}

1. Nadeem N, Khan H, Fatimi S, Ahmad MN. Giant multiple intrabdominal hydatid cysts. J Ayub Med Coll Abbottabad. 2006; 18(4):71-3.

2. Jain S, Khanduri S, Sagar UF, Yadav P, Husain M. Abdominal hydatidosis: Unusual and usual locations in a North Indian Population. Cureus. 2019 3; 11(4): 4380 .

3. Akbulut S, Ozdemir F. Intraperitoneal rupture of the hydatid cyst: Four case reports and literature review. World J Hepatol 2019 11(3): 318-29

4. Vaidya VM, Zende RJ, Paturkar AM, Gatne ML, Cystic echinococcosis in animals and humans of Maharashtra State, India. Acta Parasitologica 2018; 63:232-43

5. Greco S, Cannella R, Giambelluca D. Complications of hepatic echinococcosis: Multimodality imaging approach. Insights Imaging. 2019; 10 (1):113.

6. Rawat S, Kumar R, Raja J, Singh RS, Thingnam SK. Pulmonary hydatid cyst: Review of literature. J Family Med Prim Care. 2019; 8 (9): 2774-8

7. Giambelluca, D., Cannella, R., Caruana, G. The "serpent sign" in hydatid disease. Abdom Radiol 2018; 43: 2523-24.

8. Sarkar M, Pathania R, Jhobta A, Thakur BR, Chopra R. Cystic pulmonary hydatidosis. Lung India. 2016; 33(2):179-91. 
9. Yaghoobi MH, Sabahi MM, Zibaei M. Imaging features of the lungs hydatid cyst disseminated into the brain and spleen. Radiol Case Rep. 2019; 14 (8):903-5.

10. S M Betharia, Neelam Pr, Vidushi S, Mahindrakar A, Seema K. Disseminated Hydatid Disease involving orbit, spleen, lung and liver. Ophthalmologica 2002; 216(4):300-4.

11. Petrov D, Athanassiadi K. Hydatid disease of the lung. Eur Respir Monogr 2013; 61:107-21.

12. Bajpai Ji, Jain A, Kar A, Kant S, Bajaj D “Necklace in the lung:" Multilocularis hydatid cyst mimicking leftsided massive pleural effusion. Lung India 2019; 36 (6): 550-52.

13. Omar L, El Mehdi S, Rida A, Moulay O, Mohammed K. Hydatid cyst of limb soft tissues (11 Cases). J Infect Dis Ther 2019, 7(1): 391
14. Rahul D, Anthony A. Oyekunle Cassandra O. Ruptured pulmonary hydatid cyst following the use of Albendazole. Am J Trop Med Hyg. 2018; 98(6): 1555-6.

15. Vedat D, Selin K, Metin K, Ilhan K, Fatih A, Ertugrul G. Primary splenic hydatidosis. Dig Surg 2003; 20:38-41

16. Cankorkmaz L, Korğalı E, Atalar MH, Köylüoğlu G Case Report: Isolated renal hydatid cyst in a boy. Turkiye Parazitol Derg. 2019 17; 43(2):89-91.

17. Alam S, Umer US, Gul S, Ghaus S, Farooq B, Gul F. Uncommon sites of a common disease - Hydatid cyst. J Postgrad Med Inst 2014; 28(3):270-6.

18. Eylul G, Demet E, Dilara O, Fulya C. Unusual locations of hydatid disease: A 10-year experience from a Tertiary Reference Center in Western Turkey. Ann Diagn Pathol 2017; 29:37-40.

\begin{tabular}{|c|c|c|c|}
\hline \multicolumn{4}{|c|}{ AUTHORSHIP AND CONTRIBUTION DECLARATION } \\
\hline Sr. \# & Author(s) Full Name & Contribution to the paper & Author(s) Signature \\
\hline 1 & Muhammad Umar Amin & Article writing, Data collection. & \\
\hline 2 & Mobeen Shafique & Article writing, Data collection. & \\
\hline 3 & Mohsin Saif & Discussion writing, resutls & M. Sai \\
\hline 4 & Nawaz Rashid & $\begin{array}{l}\text { calculation. } \\
\text { Resutls calculation and data }\end{array}$ & \\
\hline 5 & Muhammad Adil & $\begin{array}{l}\text { collection. } \\
\text { Article writing, Data collection. }\end{array}$ & \\
\hline
\end{tabular}

